\title{
Emocionar-se no MCT-PUCRS
}

\author{
Alice Petry da Silva ${ }^{1}$ \\ Luiz Elcides Cardoso da Silva ${ }^{2}$ \\ Nize Maria Campos Pellanda ${ }^{3}$
}

\section{RESUMO}

O presente artigo consiste em apresentar uma narrativa de uma saída de campo pelos bolsistas da pesquisa intitulada "Na ponta dos dedos: o iPad como instrumento complexo de cognição/subjetivação”, ao MCT-PUCRS (Museu de Ciências e Tecnologias da PUCRS), com 4 crianças diagnosticadas com Transtorno do Espectro Autista (TEA). Através do projeto utilizamos o iPad para o acoplamento dos sujeitos com a realidade. Neste passeio especificamente, nossas percepções se deram em relação às emoções que os sujeitos demonstraram frente as suas descobertas durante a visitação as dependências do museu. Nesta escrita abordaremos as emoções disparadas durante a vivência destas crianças em um ambiente novo e desafiador para elas.

Palavras-chave: Autismo. Emoções. iPad. Complexidade.

\section{ABSTRACT}

The present article consists in presenting the narrative of a fieldwork made by scholarship students of the research entitled "At your fingertips: the ipad as a complex instrument of cognition/subjectivation", to the MCT-PUCRS (Museu de Ciências e Tecnologias das PUCRS), with 4 children diagnosed with Autism Spectrum Disorder (ASD). Throughout the project we used the iPad for linking the subjects with reality. In this fieldwork specifically, our perceptions were mainly in relation to the emotions that the subjects manifested facing their new discoveries during the visitations to the museum rooms. In this article we will approach the emotions triggered during the experiences of these children in a challenging new enviroment.

Key-words: Autism. Emotions. iPad Complexity.

\section{INTRODUÇÃO}

Esta pesquisa está vinculada ao "Grupo de Ações e Investigações Autopoiéticas" (GAIA), sob orientação da professora Nize Maria Campos Pellanda. Este grupo tem como seu eixo de convergência a Educação e Complexidade. O conceito central organizador das pesquisas vinculadas ao GAIA é a construção do conceito complexo de ONTOEPISTEMOGÊNESE, termo este que utilizamos para designar os processos de

\footnotetext{
${ }^{1}$ Aluna do Curso de Pedagogia da Universidade de Santa Cruz do Sul.

${ }^{2}$ Colaborador do Grupo de Ações e Investigações Autopoiéticas da Universidade de Santa Cruz do Sul.

${ }^{3}$ Professora do Departamento de Educação da Universidade de Santa Cruz do Sul.
} 
emergência do conhecer e do subjetivar-se de forma integrada no próprio processo do viver. Os temas predominantes das pesquisas são: epistemologia da complexidade, acoplamento tecnológico, Transtorno do Espectro Autista, sofrimento e autonarrativas.

No caso desta escrita, iremos abordar uma saída de campo que realizamos com quatro sujeitos diagnosticados com TEA (Transtorno de Espectro Autista) até o MCT-PUCRS. Na saída de campo podemos perceber como os sujeitos se comportaram em ambientes diferentes e com mais pessoas, já que nos nossos encontros nas dependências da UNISC - Universidade de Santa Cruz do Sul participam apenas o sujeito e os bolsistas/pesquisadores.

Durante a visitação no museu, eles puderam experimentar dos seus cinco sentidos (tato, olfato, audição, paladar e visão) o que acarretou na demonstração de diferentes emoções concomitantes. Tentaremos no decorrer do texto cartografar nossas percepções junto a eles. No entanto, muito do que se vivenciou neste dia foge da esfera do dizível.

\section{NA PONTA DOS DEDOS: O IPAD COMO INSTRUMENTO COMPLEXO DE COGNIÇÃO/SUBJETIVAÇÃO}

O projeto "Na ponta dos dedos: o iPad como instrumento complexo de cognição/subjetivação” está voltado ao acoplamento de crianças autistas através do iPad, no qual estão sendo desenvolvidos processos inovadores em termos de compreensão do papel do objeto técnico na cognição. Nesta pesquisa temos como objetivo retirar a criança do seu meio habitual, fazendo com que ela se perturbe e tenha a necessidade de reorganizar-se.

Usamos a tecnologia digital em sua versão touch para trabalhar com sujeitos diagnosticados com TEA adotando assim uma atitude complexa que rompe com o paradigma clássico. Os tratamentos tradicionais e ainda predominantes do autismo hoje reforçam as rotinas e limitam as crianças a repetições com receio de causar perturbações à estes sujeitos, o que estaria em desacordo com as referidas pesquisas.

No entanto, começam a surgir estudos baseados principalmente em neurociências, que apontam para novas direções em relação ao autismo. Este é o caso de Vanessa Marocco, Daiane Keller e Luiz Silva com suas dissertações de mestrado (MAROCCO, 2012), (KELLER, 2013) e (SILVA, 2016) e Carla Vasques (VASQUES, 2008), com sua tese de doutorado. Além destes trabalhos citados, destaco também os estudos realizados pelo GAIA na UNISC, que é pioneiro na utilização de pressupostos da cibernética e o autismo, através da utilização de tecnologias touch screen, no caso com o iPad. 
As neurociências apontam em seus estudos mais recentes a importância da autoorganização, baseada nos ruídos emitidos pelo ambiente, conforme podemos perceber em Bruno (2008):

A plasticidade cerebral é fato e indica que a possibilidade de novas conexões celulares ao longo de sua existência é extraordinária. Quanto mais rico for o ambiente, de modo a estimular atividades mentais, maior o impacto sobre as capacidades cognitivas e da memória. Tais descobertas mostram também que o cérebro se desenvolve e cresce ao longo da vida, com destaque maior para a infância, adolescência e início da idade adulta, e em menor intensidade nas outras fases da vida.

Desta forma, proporcionar ambientes desafiadores, que fujam de rotinas prédeterminadas é uma das apostas das nossas pesquisas. No caso de nossa visita ao museu, a intenção principal foi propiciar novas organizações nestes sujeitos através dos experimentos e tecnologias disponíveis em um ambiente muito diferente ao que eles estão acostumados.

Neste projeto de pesquisa apostamos muito na plasticidade neuronal e no sistema háptico dos sujeitos envolvidos. Pesquisas recentes têm mostrado que o toque na ponta dos dedos pode fazer disparar mecanismos neurofisiológicos importantíssimos (SANTAELLA, 2004). Buscamos também romper com a abordagem tradicional do autismo que reforça as estereotipias típicas investindo no princípio da complexificação e no conceito de autopoiesis de Maturana e Varela (2001), no princípio de auto-organização de Von Foerster (1996), e na teoria da aprendizagem pelo ruído de Henri Atlan (1992).

Não é necessário mais ficar discutindo se as tecnologias contribuem ou não para o nosso processo cognitivo. Hoje a tecnologia digital já faz parte da vida da maioria das pessoas e principalmente a esta nova geração de crianças. Ultrapassamos esta fronteira e passamos a partir de então a considerá-las como parte integrante do nosso processo de viver. Presenciamos a cada dia cenários potencializados pelas tecnologias na vida e em se tratando de autistas podemos utilizar esta potência como meio de emergir a subjetividade e a cognição através do uso destas que estão cada vez mais disponíveis e acessíveis.

\section{3 É POSSÍVEL DEFINIR O AUTISMO?}

O TEA é uma patologia que envolve variadas formas de manifestações. Definir o autismo é uma tarefa um tanto complexa. Na maioria dos casos o que temos é uma descrição do mesmo, muito longe de uma definição concreta e precisa (BARTH, PASSERINO E SANTAROSA, 2005). Os estudos de Kanner (1943) tornaram-se referências para a maioria dos profissionais que trabalham com autistas. Nestes, algumas controvérsias são apontadas por 
profissionais, as quais acabam por gerar algumas dúvidas nos seus apontamentos e critérios para definir as características e os sintomas dos portadores de TEA.

Atualmente, sabe-se que o autismo não é uma doença única, mas sim trata-se de um transtorno que engloba várias sindromes neurológicas. Segundo Cavalcanti (2007, pp.24 e 25), “nada mais difícil de conceituar que o autismo”, devido as várias abordagens dadas tanto pela medicina quanto pela psicologia: “a neurologia descreve como uma síndrome (...) a psiquiatria divide-se entre a tendência a considerá-lo um distúrbio psicoafetivo ou uma doença geneticamente determinada”.

Conforme a ASA - Autism Society of American, o autismo é uma deficiência complexa que tipicamente aparece durante os três primeiros anos de vida e afeta a capacidade da pessoa se comunicar e interagir com os outros. O autismo é definido por um certo conjunto de comportamentos e é um "transtorno do espectro", que afeta indivíduos de forma diferente e em diferentes graus. Não há uma causa única conhecida de autismo.

De acordo com os autores, Gadia (2006), Gauderer (1997), e Kathryn (1996) bem como as informações do site da "Diagnostic and Statistical Manual of Mental Disorders (DSM-5)”, em português, Manual Diagnóstico e Estatístico de Transtornos Mentais, lançado em maio de 2013 e disponível em www.dsm5.org, o autismo se manifesta invariavelmente antes dos 30 meses de vida. A doença é crônica e os seus portadores podem levar uma vida independente, quando apresentam sinais mínimos, ou então dependerem para o restante de suas vidas de outras pessoas para auxilio. Em contrapartida, existem profissionais que acreditam ser muito arriscado até os 30 meses de vida de uma criança, apontar que ela possui TEA, conforme podemos verificar em Cavalcanti (2007, p. 20),

\footnotetext{
a nossa clínica com crianças, que chegaram ao tratamento antes de completar três anos, mostrou-nos a impossibilidade e o perigo do diagnóstico e do prognóstico nesta tenra idade, levando-nos a interrogar a pertinência e utilidade do conceito autismo.
}

Muitas vezes o autismo é retratado com uma visão romantizada ou até mesmo dramática, porém a realidade é muito diferente. Descrever um autista é uma tarefa muito complexa, pois são seres únicos com pensamentos diferentes dos nossos, mas com necessidades semelhantes. Hoje já é aceito que o autismo deriva de muitos fatores, desde a genética até as condições ambientais, porém não sabemos as proporções de cada um.

Segundo a National Society for Autistic Children, o autismo é “... uma inadequacidade no desenvolvimento que se manifesta de maneira grave, durante toda a vida”(GAUDERER, 1993, p. 11). Até pouco tempo, o autismo era entendido como uma esquizofrenia intanfil ou 
como alguma outra doença mental. Existe um conjunto de critérios aceitos pela Organização Mundial de Saúde (OMS) para considerar um sujeito com autismo, entre eles:

- limitadas condutas verbais e comunicativas;

- trato repetitivo de objetos;

- relações sociais anormais;

- comportamento repetitivo;

- autoestimulação.

Em vista disso podemos perceber o quão difícil e complexo é chegar a um conceito do que é o autismo, mas temos como base que existem muitas variações patológicas, e a parte mais afetada está ligada com a comunicação e interação social. Além disso, é considerada uma doença crônica.

\section{EMOÇÕES SÃO IMPORTANTES?}

É sabido que os portadores do TEA têm grande dificuldade em demonstrar suas emoções, porém isso não significa que eles não as sintam. Todo comportamento tem como impulso uma emoção. As pessoas têm a capacidade de mudar o emocional de outra e viceversa e com os autistas não seria diferente. Ao demonstrá-las, os sujeitos se permitem compartilhar interesses e se desenvolverem socialmente.

De acordo com Maturana (1998, p.22), “as emoções são diferentes domínios de ações possíveis nas pessoas e animais, e as distintas disposições corporais que os constituem e realizam”. Não existe uma ação sem uma emoção que a torne um ato. Para Maturana, existe uma emoção base que faz com que todas as outras aconteçam que é o amor. O amor faz com que as nossas interações com os outros façam do outro um legítimo na convivência. “As interações recorrentes no amor ampliam e estabilizam a convivência; as interações recorrentes na agressão interferem e rompem a convivência’’ (MATURANA, 1998, p.22).

“Não é a razão que nos leva a ação, mas a emoção” (MATURANA, 1998, p. 23). Toda vez que escutamos alguém dizer que é racional e não emocional esse sujeito está sendo levado pela emoção. Quando falamos em mudar algo em nossa convivência com outros sujeitos, mas a mudança não acontece, é porque falamos com a razão, porém agimos com a emoção. "Conheceremos suas emoções como fundamentos que constituem suas ações. Não conheceremos o que poderíamos chamar de seus sentimentos, senão o espaço de existência efetiva em que esse ser humano se move” (MATURANA, 1998, p. 23). 
Segundo Maturana (1998, p. 22), “o amor não é nada especial, e sim o típico da vida humana”. Além disso, é o fundamento do social, porém nem toda convivência é social. É a emoção que constrói o domínio de condutas em que se dá a aceitação de outro individuo, e esse é o modo de convivência, desta forma é possível afirmarmos que o amor funda o social.

Vivemos em um mundo que desvaloriza as emoções em função da razão, na ideia de dizer que nós seres humanos somos diferentes por sermos racionais. Porém, somos mamíferos, sendo, assim, animais que vivem em função das emoções. As emoções são dinâmicas corporais que especificam os domínios de ação em que nos movemos (MATURANA, 1999). Nada fazemos sem que ocorra uma emoção que nos mova a tal ação.

O estreitamento do viver humano se dá através do entrelaçar das emoções e a linguagem fluindo em ações e emoções. Chamamos isso de conversar. Vivemos em grandes redes de conversação que se entrelaçam na realização de nossas individualidades corporais. Para entender o ser humano não devemos observar suas ações e sim suas emoções.

“Todo ser humano é potente de emoções” (DAMÁSIO, 2000, p.55). Segundo Silva (2016, p.54), “as emoções estão presentes nos momentos, nas vivências e nos acontecimentos. Um sorriso, choro, momento de raiva, alegria, medo ou angústia, são situações que podemos utilizar para descrever as emoções”.

Para Damásio (2000), as emoções podem ser classificadas em diferentes níveis: primárias ou universais, secundárias ou sociais e emoções de fundo. Podemos considerar as primárias como: alegria, tristeza, medo, raiva, surpresa e repugnância. Já as secundárias englobam: embaraço, ciúmes, culpa e orgulho. E as de fundo, como bem-estar ou mal-estar, calma ou tensão.

Emoções são um conjunto de reações químicas e neurais, formando um padrão; todas as emoções têm algum tipo de papel regulador a desempenhar, levando, de um modo ou de outro, à criação de circunstâncias vantajosas para o organismo em que o fenômeno se manifesta; as emoções estão ligadas a vida de um organismo, ao seu corpo, para ser exato, e seu papel é auxiliar o organismo a conservar a vida. (DAMÁSIO, 2000, pp.74,75).

Já dizia Francisco Varela, biólogo e filósofo chileno, “conhecer, fazer e viver não são coisas separáveis e a realidade assim como nossa identidade transitória são companheiros de uma dança construtiva” (PELLANDA, 2009, p.37). Através dessa passagem começamos a perceber a necessidade de conhecer novos ambientes e pessoas, e muito, além disso, observar as diferentes emoções que podem ser esboçadas ao unir o novo com o habitual. 


\section{EMOÇÕES X AUTISMO NO MCT-PUCRS}

Durante a visitação e através das observações feitas nos diários de bordo, foi possível verificar a grande variação de emoções, como a estranheza na chegada e a tristeza na partida, além do acoplamento das crianças com o meio tecnológico, com diferentes ambientes, e a interação com as invenções.

Os sujeitos puderam usar dos seus cinco sentidos (tato, olfato, audição, paladar e visão) o que acarretou na demonstração de diferentes emoções concomitantes. Ocorreram muitos momentos de euforia, felicidade e descoberta, além do estreitamento das relações das crianças com os bolsistas/pesquisadores, com seus acompanhantes e entre si, o que foi um dos fatos mais importantes. Também foi possível observar quais características comuns do TEA cada criança apresentava, como, por exemplo, a interação social, a comunicação e as atividades estereotipadas, restritas ou repetitivas.

Durante a viagem realizamos inúmeras anotações nos diários de bordo, onde pudemos perceber os sentimentos e as emoções que afloravam conforme o ruído (ATLAN, 1992) que os mesmos eram apresentados. De hora em diante passaremos a descrever parte de nossas anotações/percepções. Não é possível descrever todas as emoções sentidas durante a visitação, pois as crianças e seus acompanhantes tiveram total liberdade para decidir quais locais gostariam de visitar e acabaram não ficando por tempo integral com o acompanhamento dos pesquisadores.

- Sujeito A: ao chegar à universidade, queria ir para a sala de atendimentos ao invés de entrar na van que nos levaria ao MCT-PURS. No museu esboçou muito espanto, mas no decorrer da visitação sorriu e gargalhou muito. Manteve-se com os pais durante toda a visitação, porém indo onde desejasse. Teve uma atração maior pelos inventos relacionados com o corpo humano e principalmente pelo invento que era possível selecionar determinada parte do corpo de um boneco para que este apresentasse um movimento. Ao encontrar os pesquisadores na cafeteria foi logo até eles deixando os pais em outra mesa. Após sair da cafeteria fomos conhecer a parte do museu relacionada aos animais, porém sentiu um pouco de medo, pois os ruídos emitidos pelos animais eram muito altos. Ao entrar na van para realizar o retorno à universidade, decidiu voltar no banco com os pesquisadores que o acompanham no projeto. Este foi um momento muito feliz, pois voltou brincando e gargalhando durante toda a viagem. 
- Sujeito B: chegou à universidade e foi direto para a van. Ao ganhar um pacote de bolachas de sua mãe no caminho, dividiu com o restante do grupo sem hesitar, porém, ao passar pelo shopping, chegando próximo ao museu, se desorganizou, pois gosta muito de visitar o shopping e só passamos nas redondezas. Ao chegar no museu ficou triste por não ser o shopping e chorou um pouco, mas em seguida já estava sorrindo e se divertindo bastante com os experimentos da área de física. Teve liberdade de sua mãe para ir onde desejasse, ficou bastante atraído pelo invento de alfinetes que não machucavam, onde pode colocar a mão e fazer o desenho da mesma em relevo. Brincou no invento de girar a partir do peso do corpo sem medo e quis repetir. No momento em que foi avisado que iríamos embora, chorou e não queria voltar. Estava falante, e se envolveu bem com os pesquisadores. A mãe relatou que está mais desenvolvido.

- Sujeito C: chegou com sua irmã e a mãe. Foram direto para a van. No caminho foi brincando com seu tablet e ficou em silêncio durante toda a viagem. Manteve-se bem mais preso com a mãe. Encantou-se com o piano, as invenções relacionadas à música e o experimento de colorir em uma tela touch. Este sujeito tem uma relação muito interessante com a música, gosta de estar sempre ouvindo música, toca violino e é visível que ele consegue sentir o ritmo da música e reproduzir em gestos com seus braços, que foi o que ele realizou durante toda a visitação na parte musical. Após um tempo dentro do museu se desorganizou, deu alguns gritos e chorou um pouco, o que fez com que a mãe o levasse para a cafeteria onde havia menor aglomeração de pessoas. Ele demorou a se reorganizar. No momento do lanche ficou tentando chamar a atenção dos pesquisadores. Durante a volta para casa interagiu com os pesquisadores e com a irmã, porém se sentiu um pouco irritado com o tempo de viagem.

- Sujeito D: chegou com seu pai e se manteve com ele e em silêncio durante toda a viagem. Teve bastante liberdade de seu pai, que o seguiu por onde ele gostaria de passear, mas acabou não ficando muito próximo dos pesquisadores. Ficou encantado pelos dinossauros, sorria muito ao passear por essa área e demonstrou muita curiosidade por estes animais. Podemos perceber que ele está bem desenvolvido e autônomo, pois circulou sozinho dentro do museu sem pedir auxílio. Na volta interagiu mais com os bolsistas dentro da van, dividindo bolacha, suco e brincando. Era perceptível como estava se sentindo realizado após a visitação. Foi relatado pelo pai que ele falou dos dinossauros e do museu durante toda a semana após a visitação. Os registros fotográficos foram feitos por seu responsável, que não as cedeu. 
Acima foram relatadas algumas emoções que considero importantes, dentre elas euforia, espanto, alegria, sorrisos, medo e susto. Além disso, momentos que se tornaram únicos, como, por exemplo, o Sujeito A voltar sentado ao meu lado e deixar seus pais no banco de trás, e também me abraçar antes de ir embora, que após algumas observações seria o seu método de me agradecer; o Sujeito B se acalmar na chegada ao museu após que eu explicar para ele onde estávamos e o que iríamos fazer; o Sujeito $C$ aceitar brincar de colorir comigo no computador touch e o Sujeito D dividir um pacote de bolachas comigo quando estávamos retornando para a universidade.

\section{CONSIDERAÇÕES FINAIS}

Foi através da imersão na ontoepistemogênese que passei a dedicar um olhar mais atento ao TEA. Acredito que conhecer novos espaços, bem como diferentes tecnologias, contribui para tal.

A partir das emoções desencadeadas foi possível perceber que os sujeitos estavam gostando muito daquele momento, que era uma experiência única para todos, pois ficaram muito eufóricos a cada novo experimento descoberto, principalmente os que mais lhes chamavam atenção, tais como os das áreas musicais, corporais, animais e até mesmo os físicos que são considerados mais complexos, e, além disso, a tristeza ao anunciarmos que nossa visitação estava chegando ao fim.

Essa nova vivência foi muito importante para o andamento do projeto. Por meio dela podemos perceber como cada um reage em um ambiente novo e desafiador, e, além disso, como são únicos e singulares.

No decorrer da saída de campo e durante as pesquisas realizadas para o desenvolvimento deste artigo, pode-se perceber a importância de tirar o autista do seu meio habitual fazendo com que ele tenha a necessidade de reorganizar-se, pois isso contribui em seu desenvolvimento.

Um dos pontos mais altos desta pesquisa se deu a partir da percepção de que estavam entendendo o meio em que estavam vivendo naquele determinado momento, e o mais importante estavam conseguindo se relacionar entre si, com os pesquisadores e demais participantes. Posso acrescentar que a maioria conseguiu se acoplar com facilidade ao novo ambiente proposto. 
Com base na visita ao Museu de Ciências e Tecnologias da PUCRS, me arrisco a dizer que crianças diagnosticadas com o Transtorno do Espectro Autista têm emoções, vivem intensamente cada momento e crescem a cada passo que dão.

\section{REFERÊNCIAS}

ASA - Desenvolvido pela Autism Society of America. Apresenta informações sobre o autismo. Disponível em: <www.autism-society.org>. Acesso em 15 jan. 2017.

DSM-5 - Diagnostic and Statistical Manual of Mental Disorders - $5^{a}$ ed. Disponível em: <www.dsm5.org>. Acesso em 20 fev. 2107.

ATLAN, H. Entre o cristal e a fumaça. Rio de Janeiro: Zahar, 1992.

BARTH, C., PASSERINO, L. M.; SANTAROSA, L. M. C. Descobrindo emoções: software para estudo da teoria da mente em sujeitos com autismo. Renote, Porto Alegre, v.3, n.1, mai. 2005. Disponível em: <http://goo.gl/SZfRWo>. Acesso em 15 jan. 2017.

BRUNO, A. R. Aprendizagem integradora e a didática online: contribuições para a formação do educador. In: III Congreso Mundial de Estilos de Aprendizaje, 2008, Cáceres. Anais online, Cáceres, 2008, p. 1-17. Disponível em: <http://goo.gl/mJ9mAi>. Acesso em 02 dez. 2016.

CAVALCANTI, A. E. Construções e desconstruções. São Paulo: Casa do Psicólogo, 2007.

DAMÁSIO, A. O mistério da consciência. São Paulo: Companhia das Letras, 2000.

GADIA, C. Aprendizagem e Autismo. In: ROTTA, N. T.; OHLWEILER, L.; RIESGO, R. dos S.Transtornos da Aprendizagem Abordagem Neurobiológica e Multidiciplinar. Porto Alegre: Artmed, 2006. p.423-433.

GAUDERER, C. Autismo e outros atrasos do desenvolvimento - uma atualização para os que atuam na área: do especialista aos pais. Brasília: Corde, 1993.

. Autismo e outros atrasos do desenvolvimento. Rio de Janeiro: Revinter, 1997.

KANNER, L. Autistic Disturbances of Affective Contact. Nervous Child, n. 2, 1943. p.217250.

KATHRYN, E. Autismo. Rio de Janeiro: Revinter, 1996.

KELLER, D. S. Na ponta dos dedos: reflexões complexas entre cibernética e aprendizagem de crianças autistas. 2013. 58 f. Dissertação Programa de Pós-Graduação em Educação Mestrado - Universidade de Santa Cruz do Sul, Santa Cruz do Sul, 2013. 
MAROCCO, V. Sujeitos com autismo em relações: educação e modos de interação.2012, 159 f. Dissertação, Programa de Pós-Graduação em Educação - Mestrado e Doutorado Universidade Federal do Rio Grande do Sul, Porto Alegre, 2012.

MATURANA, H.; VARELA, F. A árvore do conhecimento: as bases biológicas da compreensão humana. São Paulo: Palas Athena, 2001.

MATURANA, H. Emoções e Linguagem na Educação e na Política. Belo Horizonte, Editora UFMG, 1998.

PELLANDA, N. M. C. Maturana \& a Educação. Belo Horizonte, Autêntica Editora, 2009.

SANTAELLA, L. Corpo e comunicação: sintoma da cultura. São Paulo: Paulus, 2004.

SILVA, L. E. C. A ontoepistemogênese de crianças autistas através da utilização de tecnologias touch. 2016. Dissertação Programa de Pós-Graduação em Educação - Mestrado Universidade de Santa Cruz do Sul, Santa Cruz do Sul, 2016.

VASQUES, C. K. Alice na Biblioteca Mágica: uma leitura sobre o diagnóstico e a escolarização de crianças com autismo e psicose infantil.2008, 195 f. Tese de Doutorado, Programa de Pós-Graduação em Educação - Mestrado e Doutorado - Universidade Federal do Rio Grando do Sul, Porto Alegre, 2008.

VON FOERSTER, H. Las semillas de la cibernetica: obras escogidas. Barcelona: Gedisa, 1996. 